\title{
Drive safely through the pelvis - know your pelvic roads: Presacral space
}

\author{
K C D P Silva ${ }^{a}$, P J S Randombage ${ }^{\mathrm{b}}$, W I Gankanda ${ }^{\mathrm{c}}$, S N Samarakkody ${ }^{\mathrm{d}}$, I G D C llukpitiya ${ }^{\mathrm{e}}$, \\ R D Jeewantha ${ }^{\dagger}$
}

This is the fifth article in the series of articles unfolding avascular spaces of the pelvis. Authors recommend reading the series of articles starting from "Drive safely through the pelvis - know your pelvic roads: Retropubic space of Retzius” published in the Sri Lanka Journal of Obstetrics and Gynaecololgy¹.

Entry in to the presacral space is by division of the peritoneum overlying the sacral promontory. It is a thin, small retroperitoneal space situated behind the rectosigmoid which is partially covered by the mesorectum anteriorly ${ }^{2}$. Care must be taken to dissect only the peritoneum as there are numerous essential structures underlying the presacral space ${ }^{3}$.

The boundaries of the presacral space are; roof formed by the sigmoidmesentery and the peritoneum, posterior border by the sacral promontory, anterior border by the posterior surface of the rectum and mesorectum. The lateral borders are formed by the common iliac vessels, ureters and by the inferior mesenteric vessels on the left. The floor is continuous with the laevator ani muscles. It also communicates with the pararectal spaces anterolateraly.

This space contains the sacral venous plexus (lateral and medial sacral veins, and the middle sacral vessels), left and right hypogastric nerves (which connects the superior and inferior hypogastric plexuses) and the superior hypogastric plexus (the sympathetic supply to the pelvis) and the anterior longitudinal ligament of the spine 4 .

Figure 1 gives an overview of the anatomy of the pelvic spaces.

Table 1 describes the surgical procedures, which use these spaces.

Figure 2 gives a schematic representation of the presacral space.

Sri Lanka Journal of Obstetrics and Gynaecology 2020; 42: 87-90

DOI: http://doi.org/10.4038/sljog.v42i2.7945

a Senior Lecturer and Head of Department of Obstetrics and Gynaecology, Faculty of Medical Sciences, University of Sri Jayewardenepura, Sri Lanka.

b Senior Registrar in Department of Obstetrics and Gynaecology, Faculty of Medical Sciences, University of Sri Jayewardenepura, Sri Lanka.

c Senior Registrar in Department of Obstetrics and Gynaecology, Faculty of Medical Sciences, University of Sri Jayewardenepura, Sri Lanka.

d Senior Registrar in Department of Obstetrics and Gynaecology, Faculty of Medical Sciences, University of Sri Jayewardenepura, Sri Lanka.

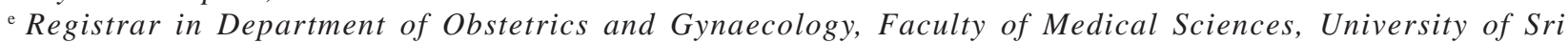
Jayewardenepura, Sri Lanka.

f Senior Registrar in Department of Obstetrics and Gynaecology, Faculty of Medical Sciences, University of Sri

Correspondence: KCDPS, e-mail: dammikesilva@sjp.ac.lk

(D) https://orcid.org/0000-0001-7438-4789

Received $1^{\text {st }}$ March 2020

Accepted $2^{\text {nd }}$ April 2020

This is an open-access article distributed under the terms of the Creative Commons Attribution 4.0 International License, which permits unrestricted use, distribution and reproduction in any medium provided the original author and source are credited. 


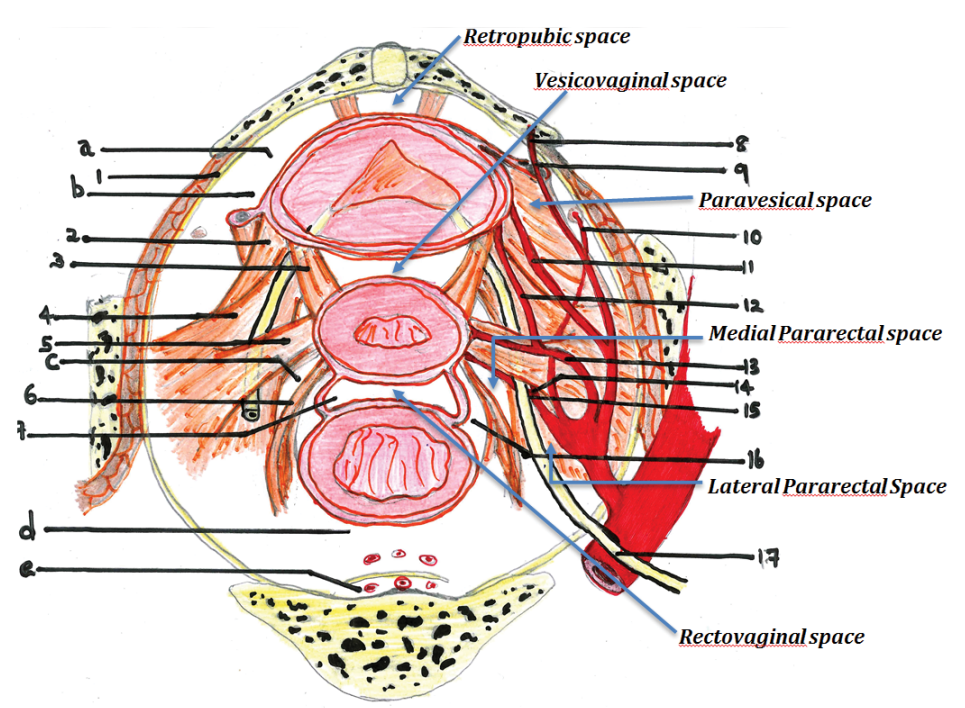

a: retropubic space; b: Paravesical space;

c: Pararectal space; d: retrorectal space;

e: presacral space

1. Parietal pelvic fascia; 2 . Lateral vesical ligament.

3. Vesico-uterine ligament. 4. Paracervix.

5. Parametrium. 6. Uterosacral ligament.

7. Recto-uterine pouch.

8. Medial umbilical ligament.

9. Umbilicovesical fascia. 10. Obturator artery.

11. Superior vesical artery. 12 . Vesicovaginal artery.

13. Uterine artery. 14. Vaginal artery.

15. Middle rectal artery. 16. Posterior vaginal fornix.

17. Ureter.

Figure 1. The schematic representation of anatomy of the pelvic spaces.

Table 1. Surgical procedures carried out in each retroperitoneal pelvic space

\begin{tabular}{|c|c|c|}
\hline Retroperitoneal pelvic spaces & & Surgical procedures carried out \\
\hline \multirow[t]{5}{*}{ Medial spaces } & Retropubic & $\begin{array}{l}\text { Burch colposuspension } \\
\text { Paravaginal repair } \\
\text { Bladder mobilization in ureteric re-implantation } \\
\text { Mesh removals }\end{array}$ \\
\hline & Vesicouterine & $\begin{array}{l}\text { Mesh repair for cystocele } \\
\text { Total laparoscopic hysterectomy } \\
\text { Radical hysterectomy } \\
\text { Vesicovaginal fistula repair } \\
\text { Bladder endometriosis resection } \\
\text { Vaginal cuff resection } \\
\text { Sacrocolpopexy / Hysterocolpopexy } \\
\text { Laparoscopic abdominal cerclage } \\
\text { Scar ectopic excision }\end{array}$ \\
\hline & Rectovaginal & $\begin{array}{l}\text { Sacrocolpopexy } \\
\text { DIE of rectosigmoid } \\
\text { Vaginal endometriotic nodule dissection } \\
\text { Bowel resection }\end{array}$ \\
\hline & Retrorectal/presacral & $\begin{array}{l}\text { Bowel resection for DIE } \\
\text { Sacrocolpopexy, sacrohysteropexy, enterocele repair } \\
\text { with a mesh }\end{array}$ \\
\hline & & $\begin{array}{l}\text { Pre-sacral neurectomy } \\
\text { Initiation of para-aortic lymphadenectomy }\end{array}$ \\
\hline Lateral & $\begin{array}{l}\text { Paravaginal } \\
\text { Paravesical } \\
\text { Pararectal }\end{array}$ & $\begin{array}{l}\text { Pelvic lymphadenectomy } \\
\text { Radical hysterectomy } \\
\text { Excision of ureteric endometriosis } \\
\text { Ureteric reimplantation/ psoas hitch } \\
\text { Bowel resection in DIE } \\
\text { Excision of endometriosis involving sacral nerve roots }\end{array}$ \\
\hline
\end{tabular}



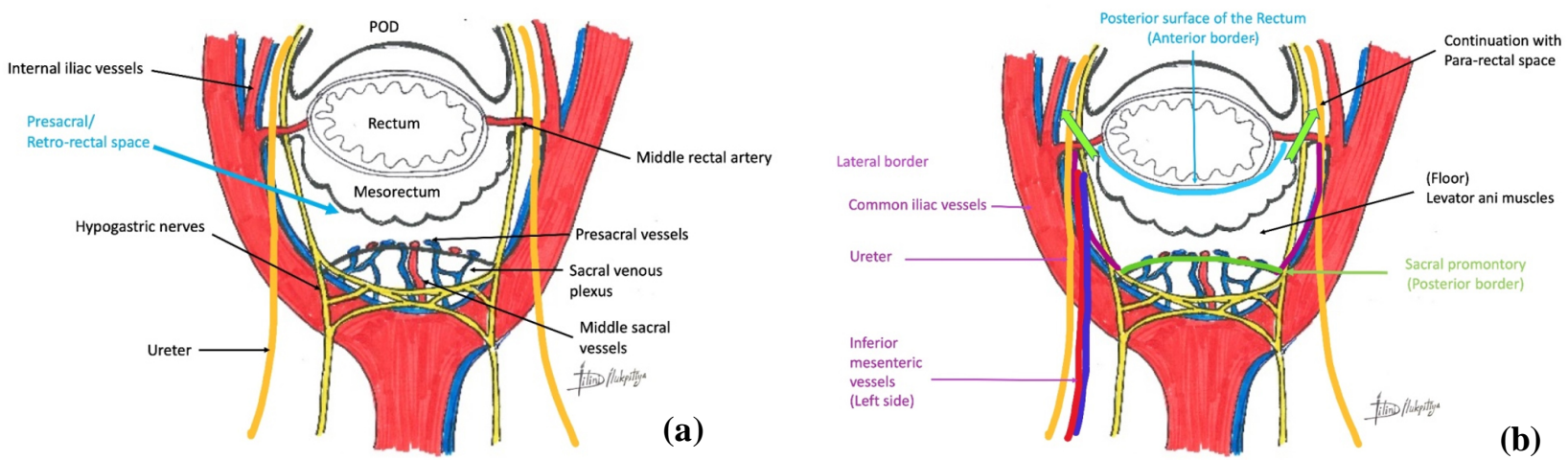

Figure 2. The pararectal space.

(a) Schematic representation of the presacral space.

$$
\begin{aligned}
& \text { List } 1 \text { - Contents of paravaginal space } \\
& \text { - Parasympathetic nerves innervating bladder } \\
& \text { - Left and right hypogastric nerves } \\
& \text { - Superior hypogastric plexus } \\
& \text { - Anterior longitudinal ligament of the spine }
\end{aligned}
$$

Sacrocolpopexy, sacrohysteropexy and sacrocervicopexy requires dissection into the presacral space. The mesh is anchored to the anterior longitudinal ligament of the vertebra with tacks orpermanent sutures. The use of metal tacks will preclude the use of MRI and therefore is discouraged; non-metallic tacks (b) Boundaries of the presacral space. maybe used instead. The author's preference is to use permanent suture material to anchor the mesh to the anterior longitudinal ligament of the vertebra. The mesh must be anchored without tension and covered by peritoneum afterwards 5 .
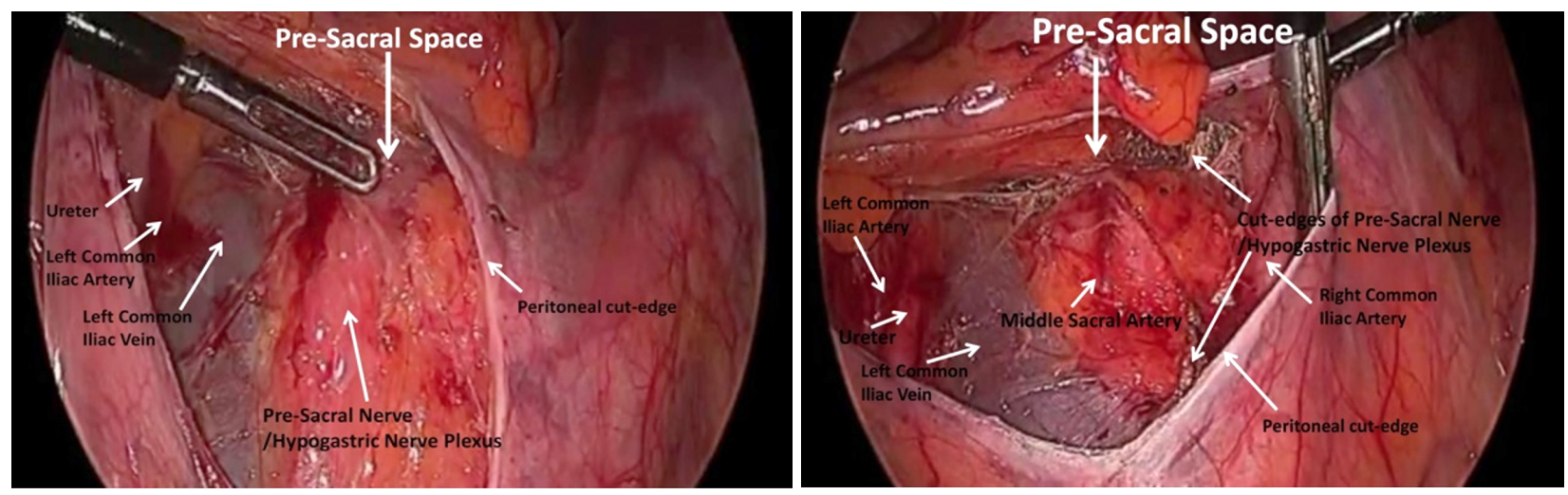

Figure 3. Laparoscopic view of the pararectal space. 
One out of four patients with central dysmenorrhea fails to respond to medical management and presacral neurectomy continues to be a useful alternative for these women. Approximately $50-75 \%$ of patients who have severe midline chronic pelvic pain will achieve a cure. It is a useful addition for women undergoing excisional surgery for deep infiltrating endometriosis. Most of the superior hypogastric nerves are located underneath the left common iliac vein and the mesentery of the inferior mesenteric artery. Therefore, it is essential to dissect carefully under these vessels to perform an effective neurectomy 5 .

Initiation of paraaortic lymph node dissection is from the sacral promontory and the usual entry is slightly below the bifurcation of the aorta. The peritoneum is lifted up as a tent from the presacral space to facilitate paraaortic lymphadenectomy.

In conclusion, the presacral space contains a number of venous vascular plexuses, important vessels and numerous nerve plexuses. Surgery in this space should be guided by meticulous anatomical knowledge. It is essential that a proper selection of suture material and needles are chosen and to have expertise in laparoscopic suturing.

Thorough knowledge about pelvic anatomy of these spaces is important for the pelvic surgeon to achieve surgical excellence while minimizing morbidity. Articles describing the other pelvic spaces will follow in future issues.

\section{References}

1. Silva KCDP, Samarakkody SN. Drive safely through the pelvis - know your pelvic roads Retropubic space of Retzius. Sri Lanka J Obstet Gynaecol. 2019; 41(2): 55.

2. Schollmeyer T, Mettler L, Ruther D, Alkatout I. Practical Manual for Laparoscopic and Hysteroscopic Gynecological Surgery [Internet]. Jaypee Brothers, Medical Publishers Pvt. Limited; 2013. Available from: https://books.google.lk/ books?id=pA0FrBYqDo4C

3. Puntambekar S, Manchanda R. Surgical pelvic anatomy in gynecologic oncology. Int J Gynecol Obstet. 2018; 143: 86-92.

4 A practical manual of laparoscopy and minimally invasive gynaecology. A clinical cookbook. $2^{\text {nd }}$ edition. 2007 Informa UK Ltd.

5. Landi S, Ceccaroni M, Perutelli A, Allodi C, Barbieri F, Fiaccavento A, et al. Laparoscopic nerve-sparing complete excision of deep endometriosis: Is it feasible? Hum Reprod. 2006; 21(3): 774-81. 